\title{
LETTER TO THE EDITOR \\ INCIDENCE OF DIABETES MELLITUS NARROWLY \\ CORRELATES WITH UNEMPLOYMENT RATE DURING 2000-2012 IN THE CZECH REPUBLIC
}

\author{
Jan Brož1, Marek Brabec ${ }^{2,3}$, Denisa Janíčková Žd'árská1, Martina Novotná4, Milan Kvapil1 \\ 'Department of Internal Medicine, 2nd Faculty of Medicine, Charles University, Prague, Czech Republic \\ ${ }^{2}$ Institute of Computer Science, Academy of Sciences of the Czech Republic, Prague, Czech Republic \\ ${ }^{3}$ Czech Institute of Informatics, Robotics and Cybernetics, Czech Technical University in Prague, Prague, Czech Republic \\ ${ }^{4}$ Ministry of Health, Prague, Czech Republic
}

Key words: diabetes mellitus, unemployment rate

Address for correspondence: J. Brož, Department of Internal Medicine, 2nd Faculty of Medicine, Charles University, V Úvalu 84, 15000 Prague, Czech Republic. E-mail: zorb@seznam.cz

http://dx.doi.org/10.21101/cejph.a4680

There is a documented association between higher unemployment rates in inner cities and a higher risk of type 2 diabetes mellitus (DM) (1). Higher unemployment at regional level is also associated with a higher prevalence of diabetes mellitus (2). Possible causes for the relationship between unemployment and diabetes mellitus include, for example, limited financial resources, which can lead to underfunded support of physical activity and healthy diets $(3,4)$. Results from the DIAB-CORE Consortium, a study that examined, among other issues, the relationship between type 2 diabetes mellitus and various social aspects including unemployment in Germany $(1,2,5)$, led us to question whether the relationship between unemployment rates and the incidence of diabetes mellitus could be confirmed for larger areas and over longer periods of time in the Czech Republic. We also wanted to determine whether previous findings of a study involving a relatively small sample of patients could be verified using a different methodology based on population data (official unemployment figures) from all 14 administrative regions of the Czech Republic.

We analyzed the relationship between the incidence of diabetes mellitus and unemployment in the Czech Republic, wherein 10,509,286 inhabitants resided during 2012 and the prevalence of diabetes mellitus was $8.0 \%$. The country is divided into 14 higher-level territorial administrative units (regions): in 2012 the least populous was inhabited by 301,726 residents, while the most populous by $1,291,816$ residents (6). Data pertaining to patients with diabetes mellitus (more specifically, the number of new diabetes patients per calendar year) were obtained from a register that is maintained by the Institute of Health Information and Statistics of the Czech Republic, to which all physicians are legally obliged to annually report data for diabetes patients in their care (7). Unemployment figures were obtained from a register kept by the Ministry of Labour and Social Affairs, which is managed in accordance with Eurostat/International Labour Office methods (8). At the time this study was conducted, available data from both registers spanned the period from 2000 to 2012 .
Given that the unemployment rates among individual regions vary both instantaneously and continuously, we compared the relationship between unemployment rates and the incidence of diabetes mellitus, while taking into account time and inter-regional differences in both population totals and background diabetes incidence. Using the Generalized Additive Model (GAM) (9), regions were represented by $i$ and calendar year was represented by $t$ :

$$
\left(\frac{\text { new DM cases }}{\text { \#of nondiabetic population }}\right)_{i t}=\mu_{i}+s(t)+\beta . \text { unemployment }_{i t}+\varepsilon_{i t}
$$

wherein the modeled quantity (the left side of the equation) is a proxy for the regionally-specific incidence. For this, the effect of unemployment was tested (regional and time-specific); coefficient $\beta$ is estimated from the data, after an adjustment for regionallyspecific average incidence $\left(\mu_{i}\right)$ and time trend $s(t)$, estimated as a spline, and $\varepsilon_{i t}$ represents homoscedastic random error.

Thus, we compared the incidence of diabetes mellitus and unemployment rate, while taking into account separate values for individual regions, over the aforementioned period of 2000-2012. The effect of unemployment on DM incidence adjusted for spatial and temporal differences was positive (the estimate of the $\beta$ coefficient was $4.173 \cdot 10^{-3}$, its standard error was $\left.7.688 \cdot 10^{-4}\right)$ and highly statistically significant $(\mathrm{p}<0.001)$. Time trend $(\mathrm{p}<0.001)$ and inter-regional incidence differences $(p<0.001)$ were significant as well.

Unfortunately, the diabetes mellitus patient registry does not distinguish types of disease in the annual new patient reports. However, the number of patients registered according to different types of diabetes mellitus in the years 2000 and 2012 was 44,870 and 56,514 individuals, respectively, with type 1 diabetes mellitus: 8,299 and 12,128 , respectively, with secondary diabetes; and 599,782 and 772,585, respectively, with type 2 diabetes mellitus. An analysis of the total increase in all diabetes mellitus patients for the given period indicated that type 2 diabetes mellitus ac- 
counted for $91.8 \%$ of all cases, while type 1 diabetes mellitus accounted only for $6.2 \%$, and secondary diabetes mellitus a mere $2.0 \%$. Due to this significant disproportion, we conclude that the calculation-proven relationship actually reflects the relationship between unemployment and type 2 diabetes mellitus.

Regardless of the degree of uncertainty concerning the type of diabetes mellitus, we consider the results to be important, given their high statistical significance.

The results suggest that unemployment influences the incidence of diabetes mellitus, indicating that DM simultaneously increases with unemployment across all 14 administrative regions in the Czech Republic and it is expected to be a trend over time. Therefore, we believe that a more detailed analysis of data from these registers could provide a more comprehensive view of the relationship between unemployment and type 2 diabetes. Such findings could later serve as a basis for prospective attempts to redistribute financial resources as well as targeted interventions to cover costs associated with the increase in diabetic patients; or even prevent further increases in the number of cases, as the case may be.

\section{Acknowledgement}

JB designed and conducted the study, performed the analysis and wrote the manuscript. MB was in charge of statistical analyses and analyzed this work, and revised the manuscript. DJZ contributed to the design of the study, and revised the manuscript. MN conducted the study, performed the analysis and revised the manuscript. MK is the guarantor of this work and, as such, had full access to all data and takes responsibility for data integrity and accuracy.

\section{Conflict of Interests}

None declared

\section{REFERENCES}

1. Müller G, Wellmann J, Hartwig S, Greiser KH, Moebus S, Jöckel KH, et al. Association of neighbourhood unemployment rate with incident Type 2 diabetes mellitus in five German regions. Diabet Med. 2015 Aug;32(8):1017-22.

2. Müller G, Kluttig A, Greiser KH, Moebus S, Slomiany U, Schipf S, et al. Regional and neighborhood disparities in the odds of type 2 diabetes: results from 5 population-based studies in Germany (DIAB-CORE consortium). Am J Epidemiol. 2013 Jul 15;178(2):221-30.

3. Auchincloss AH, Diez Roux AV, Mujahid MS, Shen M, Bertoni AG, Carnethon MR. Neighborhood resources for physical activity and healthy foods and incidence of type 2 diabetes mellitus: the Multi-Ethnic study of Atherosclerosis. Arch Intern Med. 2009 Oct 12;169(18):1698-704.

4. Auchincloss AH, Diez Roux AV, Brown DG, Erdmann CA, Bertoni AG. Neighborhood resources for physical activity and healthy foods and their association with insulin resistance. Epidemiology. 2008 Jan;19(1):146-57.

5. Müller G, Hartwig S, Greiser KH, Moebus S, Pundt N, Schipf S, et al. Gender differences in the association of individual social class and neighbourhood unemployment rate with prevalent type 2 diabetes mellitus: a cross-sectional study from the DIAB-CORE consortium. BMJ Open. 2013 Jun 21;3(6). pii: e002601.

6. Population [Internet]. Prague: Czech Statistical Office [cited 2014 Nov 1]. Available from: https://www.czso.cz/csu/czso/population.

7. Care of diabetics [Internet]. Prague: Institute of Health Information and Statistics of the Czech Republic [cited 2014 Dec 1]. Available from: http://www.uzis.cz/en/catalogue/care-diabetics.

8. Time series [Internet]. Prague: Ministry of Labour and Social Affairs of the Czech Republic [cited 2014 Dec 1]. Available from: http://portal. $\mathrm{mpsv} . \mathrm{cz} / \mathrm{sz} / \mathrm{stat} / \mathrm{nz} / \mathrm{casove}$ rady.

9. Wood SN. Generalized additive models: an introduction with R. Boca Raton: Chapman \& Hall/CRC; 2006. 